\section{Science literacy found wanting in United States and Britain}

\section{San Francisco}

More than 90 per cent of adults in the United States and Britain are scientific illiterates, according to survey results released last month at the annual meeting of the American Association for the Advancement of Science in San Francisco. Its authors claim that it is the first such survey to be carried out in both countries, allowing comparisons to be made easily.

The dismal state of scientific literacy in the United States has recently prompted renewed attention to science education. The new surveys, developed in the United States, were designed to determine whether people have a minimal level of scientific literacy. To test for a basic understanding of scientific methods, respondents were asked "what does it mean to study something scientifically?".

Answers judged correct included testing of hypothesis and building of theory, the use of experiments, or systematic

\section{RVS move opposed}

\section{London}

THE plan of the UK Natural Environment Research Council (NERC) to create a centre of excellence in oceanography at the University of Southampton will have to be redrawn to exclude the transfer of the Research Vessel Services (RVS) from Barry in South Wales, if staff at the base get their way.

The RVS provides the shipborne instrumentation, data acquisition and computer facilities necessary for marine research programmes of NERC and universities throughout the country. More than 60 of the 70 members of the RVS staff based at Barry are opposed to the move, according to one member of a committee formed to campaign against the relocation, who asked not to be named as staff have been asked not to speak to the press.

The committee has written to council members of NERC and to the secretaries of state for science and for Wales protesting against the plan, arguing that groups throughout the country rely on the services of RVS and that relocation at Southampton cannot be justified on the grounds of improved accessibility to the unit's services. They say that the move will cost $£ 10$ million, a sum that could be better spent on modernizing the equipment of the RVS. Creation of the centre at Southampton will cost $£ 35$ million over five years. The plan will go ahead if the government agrees to provide the money; an announcement is expected in the next few weeks.

Christine McGourty

comparative study. As a check on this understanding, those who answered the question correctly were then asked to say whether astrology is "very scientific", "sort of scientific" or "not scientific at all". Only those who said astrology is not scientific at all were classified as having a general understanding of how science is conducted.

Simple questions such as "does the Earth go round the Sun, or does the Sun go round the Earth?" were used to judge understanding of scientific concepts. To assess understanding of the impact of science on society, respondents were asked questions such as "is it true radioactive milk can be made safe by boiling it?". (After the Chernobyl accident, a household in Cumbria in northern England was found to be boiling milk as a protective measure.)

Only six per cent of US adults and seven per cent of British were found to have at least minimal understanding of the process, concepts and impact of science. The US results were comparable to those of earlier surveys in 1979 and 1985.

Jon Miller, director of the Northern Illinois University Public Opinion Laboratory, who carried out the US surveys, blames the widespread scientific illiteracy on inadequate education, particularly at the high school level.

But some question the validity of the surveys, claiming that they tend to overestimate illiteracy because of misunder-

\section{Washington}

Programmes to safeguard endangered species in the United States are themselves threatened by a lack of funds, says a report released at the end of January by the Government Accounting Office (GAO).

The Endangered Species Act of 1973 requires that the responsible agencies, either the Fish and Wildlife Service (FWS) of the Department of the Interior or the National Marine Fisheries Service (NMFS) of the Department of Commerce, should develop and put into action recovery programmes for species classified under the act. Although the GAO makes no attempt to assess the biological efficacy of these programmes, it finds that for $\mathbf{4 0}$ per cent of the classified species no recovery plan has been formulated, and that in the 18 cases it reviewed in detail only half of the steps in the plans have been initiated. The problem is compounded by failure of the FWS and NMFS to follow systematically the progress of its recovery plans.

Of the 482 species classified as threat-

\title{
Protection of endangered species threatened
}

standings of the questions. As an example, some members of the general public confuse astrology with astronomy.

There are interesting differences between Britain and the United States in questions relating to medicine. In a selfassessment, more US than British respondents ( 80 per cent against 50 per cent) said they are "very interested" in new medical discoveries. Similarly, about 70 per cent of US adults consider themselves "moderately" to "well informed" about such discoveries. But the high self-assessment does not translate into knowledge.

On several medical questions, US adults actually fared slightly worse than their UK counterparts. For example, 75 per cent of US respondents falsely believe that antibiotics are effective against viral infection, as against about 70 per cent of British. And although US adults were better at identifying risk factors for heart disease with more than 90 per cent correctly pinpointing smoking, lack of exercise, stress and eating too much animal fat, higher percentages of US adults (50-65 per cent) falsely believe that food additives and lack of vitamins, fresh fruit and fibre contribute to heart disease.

Miller says the dismal results in both countries are a "threat to democracy". He notes that science and technology are playing an increasing role in society but that the vast majority of people are not sufficiently literate in science to make informed decisions about major issues related to science.

Miller's solution is a radical improvement of the scope and quality of preuniversity science education.

David Swinbanks

ened or endangered, fewer than one-sixth, according to the report, are increasing in numbers, and one-third are continuing to decline. The report also identifies a failure within FWS, which is responsible for 464 of the $\mathbf{4 8 2}$ classified species, to assign priorities to various species according to its own guidelines. This is partly due to pressure from Congress, which in 1987 forced FWS to spend 11 per cent of its recovery funds on only eight species, and partly due to a perceived need by FWS to provide a strong effort in some highly visible cases, such as the American bald eagle.

The GAO lays most of the blame on a simple lack of money, as well as organizational deficiencies in FWS and NMFS. But it also recognizes that recovery of some species may be unlikely, regardless of human efforts: the fragile desert habitat of the New Mexico ridgenose rattlesnake and the Texas beaches on which Kemp's Ridley sea turtle breeds are steadily shrinking, despite conservation efforts.

David Lindley 